\title{
Valor nutritivo de refeições coletivas: tabelas de composição de alimentos versus análises em laboratório*
}

\author{
Nutritive value of collective meals: tables of food composition versus \\ laboratory analysis
}

Marisilda de A. Ribeiro, Tânia Lücia M. Stamford, José Eulálio C. Filho

Departamento de Nutriçāo da Universidade Federal de Pernambuco - Brasif

\begin{abstract}
Um ciço de 13 refeições básiças (almoço), planejadas e executadas em uma Unidade de Alimentaçăo Industrial, foi estudado para verificar concordáncia entre valor nutritivo estimado por análise indireta (tabelas de composiçăo quimica de alimentos) $\theta$ análise direta, em laboratório. Foram tomadas duas amostras de cada refeição, uma com alimentos crus nāo processada, outra com preparaçōes prontas processadas. Foram analisados: peso, matéria seca, umidade, proteínas, lipidios, fibras, cinzas, carboidratos, cálcio, ferro $\theta$ fósforo. Os resultados indicam que as tabelas de composição apresentaram correlaçāo fraca para cálcio e fósforo. Na comparação năo processada vs. processada nota-se variaçāo considerável para proteínas, cinzas, ferro e fosforo, sugerindo interferência do processamento culinário, sugerindo que as tabelas apresentam confiabilidade limitada.
\end{abstract}

Serviços de alimentą̧ão. Valor nutritivo. Tabelas de composiçāo de alimentos.

\section{Introduçäo}

Usualmente a composição química de uma refeiçāo é determinada através de tabelas cujos dados correspondem, normalmente, a alimentos isolados na sua forma crua, nāo considerando possíveis modificações durante preparo e cocção, ou o fato de os alimentos serem combinados formando preparaçōes e dietas.

Trabalhos realizados em vários pá́ses $1,3,7,17,18,19,22$ constatam a necessidade de atualização das tabelas de composiçẫo química de alimentos. Dados incompletos para alimentos e nutrientes e falta de clareza na metodologia das análises químicas são alguns dos fatores que tornam o uso dessas tabelas pouco confiáveis. No Brasil, a situação é ainda mais grave, pois as tabelas tidas como "nacionais" constituem, na verdade, compilações de tabelas estrangeiras.
Uma vez que a saúde de qualquer indivíduo ou coletividade depende primordialmente da suplência de alimento e da sua condiçăo de nutrir, o conhecimento sobre o conteúdo nutricional de alimentos e dietas é de extrema importância em saúde pública, em cujo bojo completam-se e integram-se as ações de saúde preventivas e curativas 2,6 .

O presente trabalho visa a avaliar a concordância entre valores nutritivos de refeições coletivas, estimados por tabelas de composição de alimentos e aqueles analisados em laboratório.

\section{Materlal e Método}

\section{Seleção da Amostra}

Foi utilizado como laboratório dietético, uma Unidade de Alimentaçāo Industrial, na cidade do

\footnotetext{
* Baseado na Dissertaçăo de Mestrado, sob o mesmo título "Valor nutritivo de refeiçōes coletivas: tabelas de composiça de alimentos versus análises em laboratório", apresentada à Universidade Federal de Pernambuco, em 1990.

Separatas/Reprints: Tania L.M. Stamford - Departamento de Nutriçăo da Universidade Federal de Pernambuco - Rua Prof. Nelson Chaves $s / n^{\circ}$ - Cidade Universitária - 50870-901 - Recife, PE-Brasil - Fax: (081) 271.8473

Recebido em 8.2.1994. Aprovado em 2.I.1995.
} 
Recife, com média de atendimento diário de 400 refeiçōes.

Foi analisado um ciclo de 13 refeiçð̄es de almoço, com o mínimo de 1.400 calorias, conforme exigência do Programa de Alimentação do Trabalhador (PAT) 4,5 .

\section{Coleta da Amostra}

Foram coletadas duas amostras de cada refeição, uma constituída de quantidades líquidas "per capita" de ingredientes necessários à composição e confecção de cada refeição, a qual foi chamada näo processada. Esta foi obtida durante a execuçāo das refeiçōes e o "per capita" de cada ingrediente foi determinado pela relação:

$$
\frac{\text { peso líquido total de cada ingrediente }}{\text { número estimado de refeiçōes }}
$$

A outra foi constituída de preparações prontas para serem oferecidas ao comensal e denominada processada. O "per capita" das preparações submetidas a cocção tiveram como base de cálculos o fator de rendimento de cada preparação, assim determinado:

geso da preparação pronta

peso líquido total do alimento base da preparação, cro

\section{Preparo da Amostra para Análise Química}

Seguindo técnica padronizada ${ }^{15}$, o conteúdo de cada amostra foi homogeneizado em liquidificador e triturador, ambos de porte doméstico. Do homogeneizado foi tomada alíquota de, aproximadamente, $5 \mathrm{~g}$ para determinaçåo da umidade. $O$ material restante foi espalhado em bandejas aluminizadas e postas para secar em estufa a $\pm 58^{\circ} \mathrm{C}$, constituindo-se este em material parcialmente seco, o qual foi peneirado, triturado e acondicionado em recipientes de vidro e armazenado em temperatura ambiente $\left( \pm 22^{\circ} \mathrm{C}\right)$ para posterior determinaçāo dos nutrientes.

\section{Análise das Refeições}

O valor nutritivo das refeiçð̄es foi determinado por dois métodos:

- análise indireta, estimada por tabelas de composiçāo química de alimentos de Guilherme Franco ${ }^{12}$ e da Fundação Instituto Brasileiro de Geografia e Estatística/Estudo Nacional de
Despesa Familiar ${ }^{13}$, que serão tratados por Franco e ENDEF, respectivamente. Com base nas tabelas de composição foram estimados os conteúdos de energia e nutrientes de cada refeiçāo nâo processada considerando cada alimento isoladamente, conforme se apresentam nas referidas tabelas.

- análise direta em laboratório, das refeiçozes não processada e processada, onde foram determinados os teores de matéria seca, umidade, energia e nutrientes, através de métodos analíticos padronizados $15,16,21$ e a partir da homogeneização dos componentes da refeição.

\section{Métodos Analíticos}

Através de análises químicas foram determinados os seguintes parâmetros:

- umidade: pela perda de peso em estufa regulada a $105^{\circ} \mathrm{C}^{16}$.

- cinzas ou resíduo mineral fixo: por incineração em mufla a $550^{\circ} \mathrm{C}^{16}$;

- proteína bruta total: pelo método de Kjeldahl ${ }^{16}$

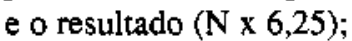

- fibra bruta: segundo o método de Hennemberg ${ }^{16}$;

- lipídios ou extrato etéreo: segundo método de extração por solventes, utilizando aparelho de SOXHLET ${ }^{16}$;

- carboidrato; calculado por diferença;

- energia: considerou-se $4 \mathrm{Kcal}$ por grama de proteína e carboidrato, e $9 \mathrm{Kcal}$ por grama de lipídio ${ }^{15}$;

- cálcio e ferro: por absorção atômica ${ }^{21}$;

- fósforo: gravimetricamente, por precipitação, na forma de pirofosfato de magnésio ${ }^{21}$.

\section{Tratamento Estatístico}

Utilizou-se a análise de variância de uma via para a comparação das médias entre os grupos, seguida do teste de Tukey, para as comparaçōes múltiplas (quando $\mathrm{F} \leq 0,05$ ).

Correlaçāo entre cada dois grupos Franco vs. não processada, Franco vs. processada, ENDEF vs. nāo processada, e näo processada vs. processada foi também empregada, com nível crítico ps 0,05 para rejeição da hipótese nula.

\section{Resultados e Discussăo}

Os valores médios e o desvio-padrão do ciclo de refeiçðes encontram-se sumarizados na Tabela 1. A 
Tabela 1 - Valores médios de parâmetros de um ciclo de refeiçōes, estimados por tabelas de composição de alimentos, e analisados em laboratório, antes e após processamento culinário.

Valores

Parâmetros

Valor Estimado

Peso (g)

Peso $(\mathrm{g})$

$\begin{array}{rr}1.138,52 & 1.138,52 \\ (81,05) & (81,05)\end{array}$

Matéria Seca (g)

Umidade (g)

- $\quad 747,10$

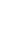

Energia (Kcal)
Proteínas (g)

$1.712,47$

$(170,81)$

$1.756,81$

74,16

$(20,68)$

$(358,23)$

Lipídios (g)

56,42

$(8,93)$

79,18

$(25,00)$

60,11

$(22,51)$

Carboidratos (g)

225,89

$(18,50)$

229,10

$(20,44)$

Cinza (g)

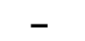

22,47

$(10,34)$

Fibras (g)

Cálcio (mg)

206,58
$(108,69)$

6,36

$(0,71)$

$(125,73)$

Ferro (mg)

18,68

$(13,58)$

20,18

$(7,78)$

Fóstoro (mg)

749,42
$(195,03)$

815,27

$(130,21)$

Franco $^{12}$ (1982)

F Análise de variância

() Desvio Padrāo

análise de variância mostra diferenças $(p<0,01)$ para peso, umidade, energia, lipídios, cálcio e fósforo. Näo houve diferença entre as médias para proteínas e ferro. Achados semelhantes em relação às proteínas são citados por outros autores 10,14 , demonstrando que em função de médias as tabelas apresentam valores concordantes para "proteína bruta". Quanto ao ferro, o resultado difere desses mesmos autores, provavelmente pelo fato de constar diariamente nos cardápios, por força do hábito regional, a preparação de feijāo, leguminosa rica nesse mineral.

$\mathrm{Na}$ Tabela 2 são observados os percentuais de diferença entre os valores estimados por análise
Valor Analisado

\begin{tabular}{|c|c|c|}
\hline $\begin{array}{c}\text { "Não } \\
\text { processada" }\end{array}$ & "Processada" & $F$ \\
\hline $\begin{array}{r}1.138,52 \\
(81,52)\end{array}$ & $\begin{array}{r}1,360,34 \\
(102,77)\end{array}$ & $117,76^{\star \star}$ \\
\hline
\end{tabular}

$\begin{array}{lll}375,00 & 364,48 & 2,04\end{array}$

$(51,34) \quad(37,48)$

$\begin{array}{lll}763,49 & 995,86 & 190,47^{* *}\end{array}$

$(85,51) \quad(106,23)$

$1.648,10$

$1.592,55$

$(211,49)$

$4,85^{\star \star}$

66,27

$(8,76)$

2,49

$(10,88)$

46,36

(15,97)

$4,40^{* *}$

$(17,75)$

227,57

$2,93^{\star}$

$(19,84)$

$(21,64)$

23,05

17,03

$(1,63)$

$3,90^{*}$

7,22

$4,41^{\text {* }}$

$(1,95)$

384,64

$(104,68)$

$16,40^{\text {* }}$

$(128,03)$

20,94

$(4,82)$

$(5,69)$

$1.031,78$

$(267,19)$

$14,67^{* *}$

$$
\begin{aligned}
& (198,51) \quad(267 \\
& \text { ENDEF13 }(1976) \\
& \star \quad-P<0,05 \\
& \star * \quad P<0,01
\end{aligned}
$$

indireta e os determinados em laboratório. No que concerne à refeição não processada, houve redução para glicídios $(\mathrm{p}<0,05)$ somente na relação com o ENDEF. Valores aumentados foram observados para cálcio e fósforo $(p<0.05)$ em relação a ambas as tabelas de composição. Coelho justifica a diferença encontrada por ela como sendo a provável quantidade de cálcio contida na água de cocção, a qual não controlou. Contudo verifica-se na relação processada vs. não processada, diferença mínima nos teores de cálcio e fósforo, sendo que a amostra não processada continha apenas a água do próprio alimento. Por outro lado, os méto- 
Tabela 2 - Percentual de diferença entre as médias estimadas pelas tabelas de composiçāo de alimentos $\theta$ analisadas em laboratório, para diversos parâmetros em um ciclo de refeiçōes, antes e após processamento culinário.

\begin{tabular}{|c|c|c|c|c|c|}
\hline Parâmetros & $\begin{array}{l}\text { "Não processada" } \\
\text { versus } \\
\text { Franco' }\end{array}$ & $\begin{array}{c}\text { "Nāo processada" } \\
\text { versus } \\
\text { ENDEF1 }\end{array}$ & $\begin{array}{c}\text { "Processada" } \\
\text { versus } \\
\text { Franco' }\end{array}$ & $\begin{array}{l}\text { "Processada" } \\
\text { versus } \\
\text { ENDEF1 }\end{array}$ & $\begin{array}{c}\text { "Processada" } \\
\text { versus } \\
\text { "Nāo processada" }\end{array}$ \\
\hline Peso (g) & 0 & 0 & $19,48^{*}$ & $19,48^{*}$ & $19,48^{*}$ \\
\hline Matéria Seca (g) & - & - & - & $\sim$ & $-2,80$ \\
\hline Umidade (g) & - & 2,19 & - & $33,30^{*}$ & 30,43 \\
\hline Energia (Kcal) & $-3,76$ & $-6,19$ & $-7,00$ & $-9,35^{*}$ & $-3,37$ \\
\hline Proteinas (g) & $-6,50$ & $-12,43$ & $-10,64$ & $-16,30$ & $-4,43$ \\
\hline Lipidios (g) & $-4,32$ & $-10,20$ & $-17,83$ & $-22,87$ & $-14,12$ \\
\hline Carboidratos $(g)$ & $-2,06$ & $-3,34^{*}$ & 0,74 & $-0,67$ & 2,85 \\
\hline Cinza $(g)$ & - & 2,58 & - & $-24,21$ & $-26,12$ \\
\hline Fibras $(g)$ & - & $\uparrow 8,71$ & - & 13,52 & $-4,37$ \\
\hline Cálcio (mg) & $90,48^{*}$ & $31,85^{*}$ & $86,19^{*}$ & $28,88^{*}$ & $-2,25$ \\
\hline Ferro (mg) & 9,74 & 1,58 & 12,10 & 3,77 & 2,15 \\
\hline Fóstoro (mg) & $49,08^{*}$ & $37,04^{*}$ & $37,68^{*}$ & $26,56^{*}$ & $-7,65$ \\
\hline \multicolumn{6}{|l|}{$\begin{array}{l}\text { Franco }^{12}(1982) \\
\text { ENDEF13 }^{(1976)}\end{array}$} \\
\hline \multicolumn{6}{|c|}{1 Percentual de diferença $=\frac{\text { Analisada }- \text { estimada }}{\text { estimada }} \times 100$} \\
\hline \multicolumn{6}{|c|}{2 Percentual de diferença $=\frac{\text { processada }- \text { não processada }}{\text { não/orocessada }}$} \\
\hline
\end{tabular}

dos utilizados no presente trabalho para determinação de cálcio e fósforo, considerados seguros e modemos, levam a aceitar como verdadeiros os teores de cálcio e fósforo encontrados. No entanto, uma vez que as tabelas se referem a alimentos isolados, os resultados permitem questionar se as diferenças podem ser atribuídas a própria mistura de alimentos e a possibilidade de interação entre seus componentes. Quanto a fibras, os resultados mostram que essas são subestimadas pelas tabelas. Considerando que o método "fibra bruta" não mede a magnitude da diferença entre as fibras alimentares e o contido nas tabelas ${ }^{9}$. infere-se que esta diferença possa ser ainda maior. No que tange à processada vs. Tabelas de Composição, observase valores acrescidos para peso, cálcio e fósforo $(p<0,05)$ em relação a ambas as tabelas e redução nos valores de energia e lipídios $(p<0,05$ ) em relação ao ENDEF. Com referência aos lipídios, embora diferença tenha sido observada somente em relação ao ENDEF, foi o nutriente que sofreu maiores variações percentuais, o que pode ter refletido nos valores de energia, uma vez que este último foi determinado por diferença. Valores analisados, inferiores aos estimados para lipídios, também foram encontrados por outros autores 11,20 que indicam variações de 2,6 até $40 \%$. A quantidade de gordura que se adere às paredes dos recipientes e a dificuldade em se determinar o que se incorpora ao alimento, assim como o questionamento sobre o método analítico utilizado, que não seria eficiente para mistura de alimentos, são alguns fatores citados para explicar tais diferenças. No presente trabalho, o método de cocção (seco e úmido ) sugere 
Tabela 3 - Coeficientes de correlação (r) entre valores estimados pelas tabelas de composição de alimentos e analisados em laboratório para diversos parâmetros, em um ciclo de refeições antes e após processamento culinário.

\begin{tabular}{|c|c|c|c|c|c|}
\hline Parâmetros & $\begin{array}{c}\text { Franco } \\
\text { versus } \\
\text { "Não processada" }\end{array}$ & $\begin{array}{l}\text { Franco } \\
\text { versus } \\
\text { "Processada" }\end{array}$ & $\begin{array}{c}\text { ENDEF } \\
\text { versus } \\
\text { "Nāo processada" }\end{array}$ & $\begin{array}{c}\text { ENDEF } \\
\text { versus } \\
\text { "Processada" }\end{array}$ & $\begin{array}{l}\text { "Não Processada" } \\
\text { versus } \\
\text { "Processada" }\end{array}$ \\
\hline Peso (g) & $1,00^{\star *}$ & $0,73^{* *}$ & $1,00^{\star *}$ & $0,73^{* *}$ & $0,73^{* \star}$ \\
\hline Matéria Seca $(g)$ & - & - & - & - & $0,81^{\star \star}$ \\
\hline Umidade $(g)$ & - & - & $0,94^{\star \star}$ & $0,86^{* *}$ & $0,84^{* *}$ \\
\hline Energia (Kcal) & $0,8^{* *}$ & $0,84^{* \star}$ & $0,92^{* *}$ & $0,88^{* *}$ & $0,81^{* *}$ \\
\hline Proteínas $(\mathrm{g})$ & $0,76^{* *}$ & 0,14 & $0,71^{* *}$ & 0,10 & 0,38 \\
\hline Lipídios (g) & 0,51 & 0,54 & $0,90^{\star \star}$ & $0,88^{* *}$ & $0,80^{* *}$ \\
\hline Carboidratos (g) & $0,85^{\star \star}$ & $0,88^{\star \star}$ & $0,88^{* *}$ & $0,88^{* \star}$ & $0,88^{\star \star}$ \\
\hline Cinza $(g)$ & - & - & $0,92^{* *}$ & 0,15 & $-0,08$ \\
\hline Fibras $(g)$ & - & - & 0,50 & 0,38 & $0,80^{* *}$ \\
\hline Cálcio (mg) & $0,48^{*}$ & 0,35 & $0,68^{\star \star}$ & $0,57^{*}$ & $0,91^{\star *}$ \\
\hline Ferro (mg) & 0,15 & 0,18 & 0,27 & 0,15 & 0,20 \\
\hline Fóstoro (mg) & 0,21 & 0,46 & 0,54 & 0,37 & 0,53 \\
\hline $\begin{array}{l}\text { Franco } 12(1982) \\
*^{*}-P<0,05\end{array}$ & & & $\begin{array}{l}\text { ENDEF } 13(1976) \\
{ }^{\star} \quad-P<0,01\end{array}$ & & \\
\hline
\end{tabular}

a interferência do processamento no quantitativo de lipídios da dieta e provavelmente, também no qualitativo. Na comparação processada vs. não processada constatam-se valores aumentados apenas para peso e umidade $(\mathrm{p}<0,05)$, o que era esperado, uma vez que a maioria das preparações como arroz, feijão e vegetais cozidos sofreram cocção úmida, que tem por finalidade hidratar o alimento. A redução observada nos teores de cinzas ( $p<0,05)$, na refeiçāo quando processada, sugere a interferência do processamento culinário, pois conhecida a propriedade de dissolução dos minerais em água, em especial o cloreto de sódio, a diferença pode ser justificada, uma vez que, preparações com carne de charque e carne de sol sofreram operações de remolho antes de seu preparo final. Por outro lado, a água de cocção de alguns vegetais, assim como a de remolho do feijão, foi desprezada.

Na Tabela 3 são apresentados os coeficientes de correlaçāo referentes a cinco condiçōes de comparação em estudo. É possível observar correlação significariva para pouco mais da metade dos valores explicitados. Para proteínas e cinzas verifica-se correlação não significativa quando a refeição é proces- sada, sugerindo a interferência do processamento culinário. Também näo significativos foram os valores para lipídios nas relações Franco vs. análises em laboratório e para ferro e fósforo nas cinco condiçães de comparação. Os baixos coeficientes de correlação verificados indicam grande variabilidade desses nutrientes nas refeiçōes individuais, a qual não pode ser detectada apenas pela comparação dos valores médios. Indicam também não haver correspondência entre valores analisados e estimados ou tendência de comportamento uniforme, o que reduz a confiabilidade nas tabelas para esses nutrientes.

Apesar de as Tabelas de Composição serem o único meio prático disponível para conhecimento do conteúdo nutricional dos diferentes alimentos e dietas, e reconhecidas as falhas nelas existentes, excassos são os trabalhos que visam a reconhecer a composição alimentar consumida pela população. Daqueles existentes, quer em nível internacional ou nacional, apresentam divergências entre si, tanto em relação aos objetivos quanto às metodologias utilizadas, fator limitante para comparaçōes e maior aprofundamento de discussões em relação aos resultados aqui apresentados. 
Quanto à hip6tese formulada, os resultados indicam que as tabelas subestimam a composição de uma refeiçāo, principalmente em relação aos minerais. Evidentemente, os resultados de um único trabalho nāo são suficientes para indicar correções definitivas que possam sanar as lacunas deixadas pelas Tabelas de Composição. Portanto, seria importante outros estudos com esta finalidade.

\section{Conclusões}

Considerando a metodologia utilizada, é possível concluir:

\section{Referêncla Bibliográficas}

1. AlVARADO, J. de D. \& ESPINOSA, S.G. Datos de composición de laimentos en el Ecuador. Arcb. Latinoam. Nutr, 37:723-9, 1987,

2. BATISTA FILHO, M. Saúde e nutriçào. In: Rouquarol, Z. et al. Epidemiologia \& saúde, $8^{2}$. ed. Rio de Janeiro, MEDSI, 1986. p. 34369.

3. BOURGES, H. Analisis de la composición de los alimentos en México: antecedentes, situación actual y perspectivas. Arcb. Latinoam. Nutr., 37:785-9, 1987.

4. BRASIL. Leis, Decretos, Portaria $n^{\circ} 652$ de 22 de dezembro de 1978. In: Ministério do Trabalho. Secretaria de Promoção Social. Tudo sobre o Programa de Alimentação do Trabalbador. Brasilia, 1987. p.23.

5. BRASIL. Leis, Decretos, Portaria $n^{\circ} 653$ de 22 de dezembro de 1976. In: Ministério do Trabalho. Secretaria de Promoção Social. Tudo sobre o Programa de Alimentação do Trabalbador, Brașilia, 1987. p. 23.

6. CHAVES, N. Integração da nutrição em saúde pública. In: Congresso Brasileiro de Nutricionistas. $3^{\circ}$, Encontro LatinoAmericano de Nutricionistas $1^{\circ}$. Rio de Janeiro, 1968. p.73.

7. CLOSA, S.J. et al. Informe sobre o estado actual, interes y limitaciones existentes con referencia a "tablas de composicion de alimentos en República Argentina". Arch. Latinoam. Nutr., 37:694-701, 1987.

8. COELHO, M.A.S.C. Composição de alimentos: avaliação de métodos em uso. Recife, 1975. [Dissertação de Mestrado - Universidade Federal de Pernambuco. Centro de Ciências da Saúde, Departamento de Nutrição].

9. FILISETTI-COZZI, T.M.C.C. \& LAJOLO, F.M. Determinação de fibra da dieta: método enzimático. In: Congresso Brasileiro de Alimentação e Nutrição, 1. São Paulo, 1987,
- as tabelas subestimam os valores de cálcio e fósforo, tanto para a refeição não processada quanto na processada.

- em função da variabilidade apresentada para proteínas, cinzas, ferro e fósforo na refeição, após processamento culinário, o uso das tabelas de composição parece limitado para o planejamento e avaliação de dietas específicas.

Sugere-se, ainda, análise de preparaçōes isoladas, assim como determinação de seus fatores de rendimento, possibilitando maior controle de modificações ocorridas pelo processamento culinário, o que seria bastante interessante e de extrema utilidade para profissionais da área de Nutrição.

Programa e resumos. São Paulo, Sociedade Brasileira de Alimentação e Nutrição, 1987. p. 142.

10. FLORES, M. \& COELHO, M.A.S.C. Nutrient intake data calculated using food composition tables: factors affecting accuracy. In: Rand, W.M. et al. Food composition data: a user's perspective. Tokyo, The United Nations Lniversity, 1985. p. 137-44.

11. FLORES, M. \& MENCHU, M.T. Evaluation dietética por analisis quimico y por calculo de composición de alimentos. Arch. Latinoam. Nutr., 18:283-300, 1968.

12. FRANCO, G. Nutrição: textos básicas e tabelas de composição de alimentos. $6^{\mathrm{a}}$ ed. Rio de Janeiro, Atheneu, 1982.

13. FLNDAÇȦO IBGE. Tabela de composição de alimentos. Rio de Janeiro, 1976. (ENDEF - Estudo Nacional de Despesa Familiar).

14. GIOVANNETTI, P.M. Calculed versus analytical nutrient values of diets in research studies. $J$. Can. Diet. Assoc., 48(2): 95-102, 1987

15. HARRIS, L.E. Compilação de dados analíticose biológicos para o preparo de tabelas de composição de alimentos para uso nos trópicos da América Latina. Gaisneville, University of Florida, Centro de Agricultura Tropical, 1970. p. 801-9.

16. INSTTTUTO ADOLFO LUTZ. Normas analíticas do Instituto Adolfo Lutz. 2a. ed., Sảo Paulo, 1976.

17. JAFFÉ, W.G. \& ADAM, G. Utilización de la tabla oficial de composición de alimentos en la actualidad. Arch. Latinoam. Nutr., 37:7304, 1987.

18. LAJOLO, F.M. \& VANNUCCHI, H. Tabelas de composiçâo de nutrientes em alimentos: situaçăo no Brasil e necessidades. Arch Latinaam. Nutr., 37:702-13, 1987.

19. LAREO, L.R. Propuesta para la elaboración de estandares estatísticos para los nutrientes presentados en la tablas de composición de 
alimentos. Arch. Latinoam. Nutr., 37:763-8. 1987.

20. OLIVEIRA, J.E.D. et. al. "Bóias-frias"- um estudo socioeconômico-nutricional sobre trabalbadores volantes rurais na area de Ribeirâo Preto. Sào Paulo, CNPq/Academia de Ciências do Estado de Sào Paulo. 1981.

21. SLDENE. Departamento de Planejamento de
Recursos Minerais. Métodos de análises minerais. Recife [s.d.]

22. WINDHAM, C.T, et al. Lsing food composition data to communicate nutrition to the consumen. In: Rand, W.M. et al. Food composition data: 'a user's perspective. Tokyo, The Lnited Nations Lniversity, 1985 . p. 83-95.

\begin{abstract}
A cycle of 13 basic meals lunches, planned and executed at an industrial feeding unit was studied, in order to verify the agreement between the nutritive value estimated by indirect analysis (Tables of chemical composition of foodstuffs), and by direct analysis in the laboratory. Two samples of each meal were taken, one consisting of raw unprocessed food and the other of prepared processed food. The following parameters were evaluated: weight, dry matter, humidity, proteins, lipids, fibers ashes, carbohydrates, calcium, iron and phosphorus. The results suggest that both the composition tables presented a weak correlation for calcium and phosphorus. Comparing processed with unprocessed meals, there was an increase in weight and humidity, and a considerabie variation in protein, ash, iron and phosphorus, suggesting interference of the culinary process. The Food Composition Tables present limited reliabity for the estimation of most nutrients in collective, prepared meals.
\end{abstract}

Food services. Nutritive value. Table of food composition. 